\title{
Active case finding: comparison of the acceptability, feasibility and effectiveness of targeted versus blanket provider-initiated- testing and counseling of HIV among children and adolescents in Cameroon
}

Habakkuk Azinyui Yumo ${ }^{1,2^{*}}$ (D), Christopher Kuaban ${ }^{3}$, Rogers Awoh Ajeh ${ }^{1}$, Akindeh Mbuh Nji ${ }^{1,4}$, Denis Nash ${ }^{5}$, Anastos Kathryn ${ }^{6,7}$, Marcus Beissner ${ }^{2}$ and Thomas Loescher ${ }^{2}$

\begin{abstract}
Background: Children and adolescents still lag behind adults in accessing antiretroviral therapy (ART), which is largely due to their limited access to HIV testing services. This study compares the acceptability, feasibility and effectiveness of targeted versus blanket provider-initiated testing and counseling (PITC) among children and adolescents in Cameroon.
\end{abstract}

Methods: During a 6-month period in three hospitals in Cameroon, we invited HIV-positive parents to have their biological children ( 6 weeks-19 years) tested for HIV (targeted PITC). During that same period and in the same hospitals, we also systematically offered HIV testing to all children evaluated at the outpatient department (blanket PITC). Children of consenting parents were tested for HIV, and positive cases were enrolled on ART. We compared the acceptability, feasibility and effectiveness of targeted and blanket PITC using Chi-square test at 5\% significant level.

Results: We enrolled 1240 and 2459 eligible parents in the targeted PITC (tPITC) and blanket PITC (bPITC) group, and 99.7\% and $98.8 \%$ of these parents accepted the offer to have their children tested for HIV, respectively. Out of the 1990 and 2729 children enrolled in the TPITC and bPITC group, 56.7\% and 90.3\% were tested for HIV ( $p<0.0001)$, respectively. The HIV positivity rate was $3.5 \%(\mathrm{Cl}: 2.4-4.5)$ and $1.6 \%(\mathrm{Cl}: 1.1-2.1)$ in the tPITC and bPITC ( $p=0.0008)$, respectively. This finding suggests that the case detection was two times higher in IPITC compared to bPITC, or alternatively, 29 and 63 children have to be tested to identify one HIV case with the implementation of tPITC and bPITC, respectively. The majority (84.8\%) of HIV-positive children in the IPITC group were diagnosed earlier at WHO stage 1 , and cases were mostly diagnosed at WHO stage $3(39.1 \%)(p<0.0001)$ in the bPITC group. Among the children who tested HIV-positive, $85.0 \%$ and 52.5\% from the TPITC and bPITC group respectively, were enrolled on ART ( $p=0.0018)$.

Conclusions: The tPITC and bPITC strategies demonstrated notable high HIV testing acceptance. APITC was superior to bPITC in terms of case detection, case detection earliness and linkage to care. These findings indicate that tPITC is effective in case detection and linkage of children and adolescents to ART.

Trial registration: Trial registration Number: NCT03024762. Name of Registry: ClinicalTrial.gov. Date registration: January 19, 2017 ('retrospectively registered'). Date of enrolment first patient: 15/07/2015.

Keywords: HIV, Identification, Children, Adolescents, Case detection, Linkage, Targeted PITC, Blanket PITC

* Correspondence: ha.yumo12@gmail.com

${ }^{1}$ R4D International Foundation, Yaounde, Cameroon

${ }^{2}$ Center for International Health (CIH), Ludwig-Maximilians-Universität,

München, Germany

Full list of author information is available at the end of the article

(c) The Author(s). 2018 Open Access This article is distributed under the terms of the Creative Commons Attribution 4.0 International License (http://creativecommons.org/licenses/by/4.0/), which permits unrestricted use, distribution, and reproduction in any medium, provided you give appropriate credit to the original author(s) and the source, provide a link to the Creative Commons license, and indicate if changes were made. The Creative Commons Public Domain Dedication waiver (http://creativecommons.org/publicdomain/zero/1.0/) applies to the data made available in this article, unless otherwise stated. 


\section{Background}

Human immunodeficiency virus (HIV) case identification has been and remains a major obstacle to the expansion of antiretroviral therapy (ART) among infants, children and adolescents in sub-Saharan Africa due to multifaceted barriers at the patient, provider, community and national policy levels [1]. The uptake of early infant diagnosis (EID) using deoxyribonucleic acid-polymerase chain reaction (DNA-PCR) techniques for infants younger than 18 months of age is sub-optimal with a global coverage of $50 \%$ [2]. This gap is due to numerous barriers, including low antenatal consultation (ANC) attendance, weak supply chain management of pediatric HIV commodities, low retention, delayed test results, weak follow-up after delivery and poor linkage to treatment [3]. Implementation of the routine or blanket provider-initiated-testing and counseling (PITC), a strategy recommended by the World Health Organization (WHO) for HIV case finding among older children ( $\geq 18$ months) is fragmentary. This situation is attributable to many factors, including fear of stigma, lack of staff training, lack of HIV testing kits, poor commitment from facility leadership, and missed parental consent to test children $[4,5]$.

As a result of these programmatic gaps, only approximately $10 \%$ and $15 \%$ of HIV-infected young (15-24 years) males and females, respectively, in Sub-Saharan Africa are aware of their HIV status [6]. As the gateway to HIV treatment and care, this low HIV testing uptake among children and adolescents translates to the current low pediatric ART coverage with only $43 \%$ of eligible children being on treatment compared to $54 \%$ of adults [7].

In Cameroon, the pediatric ART coverage gap is even wider, with only $18 \%$ of eligible children being on ART compared with $38 \%$ of adults [8]. This is happening despite the availability of HIV commodities (testing kits and antiretroviral drugs) provided free of charge for children by the government of Cameroon with the support of external funding agencies, most notably the Global Fund to fight HIV/AIDS, Tuberculosis and Malaria (GFATM) and the United States President's Emergency Plan for AIDS Relief (PEPFAR). This gap indicates the need for alternative and/or innovative approaches to increase pediatric and adolescent HIV case identification and linkage to care in Cameroon and globally.

Given that over 90\% [9] of pediatric HIV infections result from mother to child transmission, targeting with HIV testing, children of parents living with HIV/AIDS is a plausible high-yield case finding strategy as indicated by a study conducted in 2006 in Cameroon [10]. Though recommended by WHO since 2010 [11], implementation of this targeted PITC (tPITC) strategy is still sub-optimal in Cameroon and in other sub-Saharan African countries. Currently, there is a dearth of literature on the implementation outcome of
tPITC, and most importantly, there is a lack of knowledge on its comparative advantage over the blanket PITC (bPITC). This study aimed to bridge this evidence gap and to contribute to the expansion of HIV treatment and care among children and adolescents.

\section{Methods \\ Design}

We conducted an interventional study in which we invited all parents living with HIV/AIDS receiving HIV care in three hospitals in Cameroon to have their children of unknown HIV status aged 6 weeks to 19 years to be tested for HIV (tPITC group). In the same hospitals, all parents/guardians who accompanied their sick children of the same age group for consultation at the outpatient departments were also counseled, and these children were invited to test for HIV irrespective of the presenting complaint (bPITC group).

\section{Setting}

The study was conducted in the Limbe Regional Hospital (LRH), Ndop District Hospital (NDH) and Abong-Mbang District Hospital (ADH). These hospitals provide comprehensive health care services to the catchment population, including the management of HIV/AIDS. The study was conducted within the Active Search for Pediatric HIV/ AIDS (ASPA) project, an initiative of Research for Development (R4D) International Foundation, a Cameroon-based global health research non-governmental organization. The ASPA project aimed to promote pediatric HIV service delivery through a range of activities, including capacity building of health personnel, services delivery both at facility and community level, nutritional support, monitoring and evaluation.

\section{Study period and population}

Data were collected in the LRH from July to December 2015, and in ADH and NDH from June to November 2016. The study population in the tPITC group consisted of parents living with HIV/AIDS receiving care in the hospital and their children of unknown HIV status, aged 6 weeks to 19 years. Similarly, in the bPITC group, the study population consisted of parents/guardians and their sick children of the same age group who attended the hospital outpatient department for any reason. Children or parents critically ill (in vital distress) were excluded from the study.

\section{Study procedures}

\section{Site preparation}

Prior to the study, input and support provided by the project to the respective hospitals included the following: staff training on both tPITC and bPITC activities, 
provision of HIV testing kits, and human resource support (dedicated staff to support project implementation).

\section{Enrollment of participants and data collection}

In the tPITC group, HIV-positive parents in care at the HIV treatment center (ART clinic) were counseled and invited by a trained counselor to participate in the study together with their children with unknown HIV status. These parents were offered a testing opportunity for their biological children in either the hospital or at home (community testing). In the bPITC group, parents/ guardians were also counseled and invited to have their sick children tested for HIV irrespective of the reason of consultation.

In both groups, all parents/guardians who consented to participate in the study were enrolled together with their children. Pre-tested and structured questionnaires (Additional file 1: Questionaires 1-4) were used by a trained data clerk to collect socio-demographic information and the HIV/AIDS history of parents and children (Fig. 1). In the tPITC group, a sub-population of parents who initially agreed to bring their children for HIV testing, but subsequently did not, were interviewed using a structured questionnaire (Additional file 2: Questionaire 5) and this to determine the reason of their failure to bring children for testing.

\section{HIV testing, linkage and ART enrolment}

For children younger than 18 months of age, HIV testing was performed using DNA-PCR techniques. For children older than 18 months, HIV testing was performed using two HIV antibody rapid tests according to the Cameroon national guidelines. The WHO test and treat policy was not effective at the site level at the time of the study. Thus, children who tested positive for HIV were assessed for ART eligibility using WHO clinical staging

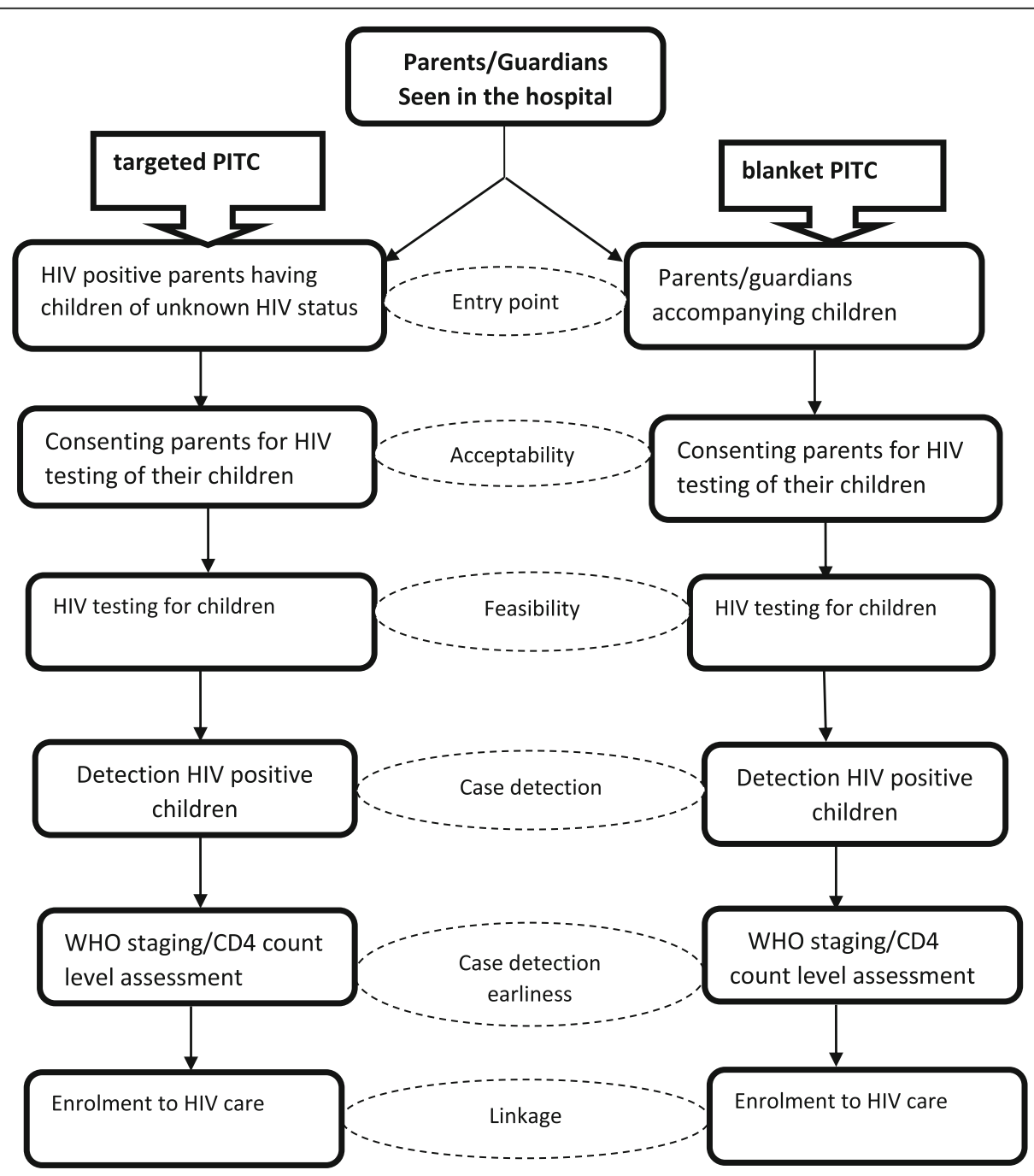

Fig. 1 Enrollment, HIV testing and linkage to care and treatment of children and adolescents, ASPA Study, July-November 2016, Cameroon 
and/or baseline biological analysis, including CD4 count. Eligible children were initiated on ART and monitored according to the Cameroon national guidelines.

\section{Sample size}

We used the following formula to calculate the sample size for 2 proportions with dichotomous outcome [12]:

$$
\mathrm{N}=\left(\mathrm{Z}_{\alpha / 2}+\mathrm{Z}_{\beta}\right)^{2} *\left(\mathrm{p}_{1}\left(1-\mathrm{p}_{1}\right)+\mathrm{p}_{2}\left(1-\mathrm{p}_{2}\right)\right) /\left(\mathrm{p}_{1}-\mathrm{p}_{2}\right)^{2}
$$

Where: $\alpha=5 \%, \beta=20 \%, p_{1}=10 \%, p_{2}=5 \%$. We found $N=432$ children and adolescents per group and per hospital or 1296 per group for the three hospitals. Thus, a total of $n=1296 \times 2=2592$ children and adolescents for the two groups and three hospitals.

\section{Data management and analysis}

Anonymous data from the questionnaires were entered into a database and analyzed using STATA 2013 (College Station, TX: StataCorp LP). The study outcomes were determined by computing the proportions and comparing the values using Chi-square test (X2) at 5\% significant level.

\section{Definitions of terms}

The study outcomes were defined and calculated as follows:

i) Acceptability (acceptance rate): proportion of parents who accepted to have their children tested among all eligible parents enrolled in the study

ii) Feasibility (HIV testing uptake rate): proportion of children who tested for HIV among all eligible children identified by the study iii) Effectiveness: It was defined and measured as follows:

a) HIV case detection/positivity rate: proportion of HIV cases detected among children and adolescents tested for HIV

b) HIV case detection earliness: proportion of cases detected at WHO stage 1

c) ART linkage rate: proportion of cases linked to care or enrolled on ART

\section{Results}

\section{Acceptability of tPITC and bPITC}

The study offered enrolment to 3699 parents, including 1240 and 2459 in the tPITC and bPITC groups, respectively. In both groups, parents were predominantly from Ndop District Hospital (38.6\%), followed by Limbe Regional Hospital (36.4\%) and Abong-Mbang District Hospital (25.0\%). Among these parents, 99.7\% (1236/1240) and $98.8 \%(2430 / 2459)$ in the tPITC and bPITC, respectively, accepted to have their children tested for HIV.

\section{Feasibility of tPITC and bPITC}

Through parents, 4719 eligible children were enrolled for HIV testing, including 1990 and 2729 in the tPITC and bPITC groups, respectively. In both groups, the children were predominantly from Ndop District Hospital Hospital (41.1\%), followed by Limbe Regional Hospital (37.2\%) and Abong-Mbang District Hospital (21.7\%) (Table 1). None of the children enrolled had refused to be tested for HIV. Among the participating children, $56.7 \%(1129 / 1990)$ and $90.3 \%(2465 / 2729)(p<0.0001)$ tested for HIV, respectively, in the tPITC and bPITC groups (Table 2). Among children $\leq 12$ years, the HIV

Table 1 Uptake of HIV services among children and adolescents in three hospitals in Cameroon, ASPA study, July 2015-November 2016

\begin{tabular}{|c|c|c|c|c|c|c|c|c|}
\hline \multirow[t]{3}{*}{ HIV services } & \multicolumn{4}{|l|}{ tPITC } & \multicolumn{4}{|l|}{ bPITC } \\
\hline & Limbe & Abong-Mbang & Ndop & Total & Limbe & Abong-Mbang & Ndop & Total \\
\hline & n (\%) & n (\%) & n (\%) & $n$ & n (\%) & n (\%) & n (\%) & $n$ \\
\hline Children and adolescents enrolled & $552(27.7)$ & $400(20.1)$ & $1038(52.1)$ & 1990 & $1205(44.1)$ & $623(22.8)$ & $901(33.0)$ & 2729 \\
\hline $\begin{array}{l}\text { Children and adolescents tested for } \\
\text { HIV in the hospital }\end{array}$ & $257(27.6)$ & $212(22.7)$ & $462(49.6)$ & 931 & $951(38.5)$ & $619(25.1)$ & $895(36.3)$ & 2465 \\
\hline $\begin{array}{l}\text { Children and adolescents tested for } \\
\text { HIV in the community (only tPITC) }\end{array}$ & $43(21.7)$ & $140(70.7)$ & $15(7.5)$ & 198 & N/A & N/A & N/A & N/A \\
\hline $\begin{array}{l}\text { Children tested for HIV (both } \\
\text { community and hospital) }\end{array}$ & $300(26.5)$ & $352(31.1)$ & $477(42.2)$ & 1129 & $951(38.5)$ & $619(25.1)$ & $895(36.3)$ & 2465 \\
\hline $\begin{array}{l}\text { Children and adolescents tested } \\
\mathrm{HIV+} \text { in the community }\end{array}$ & $0(0.0)$ & $1(100)$ & $0(0.0)$ & 1 & N/A & N/A & N/A & N/A \\
\hline $\begin{array}{l}\text { Children and adolescents tested } \\
\text { HIV+ in the hospital }\end{array}$ & $5(12.8)$ & $13(33.3)$ & $21(53.8)$ & 39 & $14(35.0)$ & $21(52.5)$ & $5(12.5)$ & 40 \\
\hline $\begin{array}{l}\text { Children and adolescents tested } \\
\text { HIV+ (both hospital and community) }\end{array}$ & $5(12.5)$ & $14(35.0)$ & $21(52.5)$ & 40 & $14(35.0)$ & $21(52.5)$ & $5(12.5)$ & 40 \\
\hline Children and adolescents initiated on ART & $1(2.9)$ & $13(38.2)$ & $20(58.8)$ & 34 & $3(14.2)$ & $16(76.1)$ & $2(9.5)$ & 21 \\
\hline
\end{tabular}


Table 2 Acceptability and effectiveness of targeted versus blanket PITC in three hospitals in Cameroon, ASPA study, July 2015November 2016

\begin{tabular}{|c|c|c|c|c|c|c|c|c|c|}
\hline \multirow[t]{3}{*}{ Outcome } & \multicolumn{4}{|l|}{ tPITC } & \multicolumn{4}{|l|}{ bPITC } & \multirow[t]{3}{*}{$P^{*}$} \\
\hline & Limbe & $\begin{array}{l}\text { Abong- } \\
\text { Mbang }\end{array}$ & Ndop & Total & Limbe & $\begin{array}{l}\text { Abong- } \\
\text { Mbang }\end{array}$ & Ndop & Total & \\
\hline & $\%(n)$ & $\%(n)$ & $\%(n)$ & $\%(n)$ & $\%(n)$ & $\%(n)$ & $\%(n)$ & $\%(n)$ & \\
\hline $\begin{array}{l}\text { Acceptability } \\
\text { rate }\end{array}$ & $\begin{array}{l}100.0(327 / \\
327)\end{array}$ & $\begin{array}{l}99.7 \text { (344/ } \\
345)\end{array}$ & $\begin{array}{l}99.6(566 / \\
568)\end{array}$ & $\begin{array}{l}99.8(1616 / \\
1619)\end{array}$ & $\begin{array}{l}99.2(1013 / \\
1021)\end{array}$ & $\begin{array}{l}99.3(575 / \\
579)\end{array}$ & $\begin{array}{l}98.0(842 / \\
859)\end{array}$ & $\begin{array}{l}98.8(2430 / \\
2459)\end{array}$ & 0.0005 \\
\hline Feasibility rate & $54.3(300 / 552)$ & $\begin{array}{l}88.0(352 / \\
400)\end{array}$ & $46.0(477 / 1038)$ & $\begin{array}{l}56.7(1129 / \\
1990)\end{array}$ & $\begin{array}{l}78.9(951 / \\
1205)\end{array}$ & $\begin{array}{l}99.4(619 / \\
623)\end{array}$ & $\begin{array}{l}99.3(895 / \\
901)\end{array}$ & $\begin{array}{l}90.3(2465 / \\
2729)\end{array}$ & $<0.0001$ \\
\hline $\begin{array}{l}\text { HIV positivity } \\
\text { rate }\end{array}$ & $1.7(5 / 300)$ & $4.0(14 / 352)$ & $4.4(21 / 477)$ & $3.5(40 / 1129)$ & $1.5(14 / 951)$ & $3.4(21 / 619)$ & $0.6(5 / 895)$ & $1.6(40 / 2465)$ & 0.0008 \\
\hline Linkage rate & $20.0(1 / 5)$ & $92.9(12 / 14)$ & $95.2(20 / 21)$ & $85.0(33 / 40)$ & $21.4(3 / 14)$ & $76.2(16 / 21)$ & $40.0(2 / 5)$ & $52.5(21 / 40)$ & 0.0018 \\
\hline
\end{tabular}

${ }^{*} p$ value comparing the outcome (total) of tPITC vs. bPITC in the 3 study sites

testing uptake (feasibility) rate was $60.5 \%$ compared to 91.2\% $(p<0.0001)$, respectively, in the tPITC and bPITC groups. In comparison, among children older than 12 years of age, this rate was $43.8 \%$ vs $86.7 \%(p<0.0001)$.

The lack of transport fare $(38.4 \%)$, children not living with biological parents (25.6\%) and lack of time (10.5\%) were the three primary reasons affecting the feasibility of tPITC strategy. These reasons were provided by a subgroup of 86 parents who initially accepted to have their children tested, but subsequently did not return to the hospital with their children for HIV testing (Fig. 2).

\section{HIV positivity/case detection}

A total of 3594 children and adolescents were tested for HIV during the recruitment period; 1129 and 2465 in the tPITC and bPITC group, respectively (Table 1). The HIV positivity rate (case detection) was $3.5 \%$ (95\% CI: 2.4-4.5) in tPITC group compared to $1.6 \%$ (95CI: $1.1-$ $2.1)$ in the bPITC group $(p=0.0008)$ (Table 2$)$. Among children $\leq 12$ years, the HIV positivity rate was $3.3 \%$ vs
1.4\% $(p=0.0006)$, respectively, in the tPITC and bPITC groups. In comparison, among children older than 12, this rate was $4.6 \%$ vs. $2.5 \%(p=0.1621)$.

In the tPITC group, 17.of children were tested in the community and the hospital, respectively. The HIV positivity rate was $0.5 \%(1 / 198)$ in children tested in the community compared $4.2 \%(39 / 931)(p=0.0107)$ among those tested in the hospital.

\section{Early detection of HIV cases}

The proportion of HIV infected children diagnosed at WHO stage 1 and WHO stage 3 were $84.8 \%$ (28/33) and $15.2 \%(5 / 33)$ in the tPITC group, respectively, compared to $21.7 \%(5 / 23)$ and $39.1 \%(9 / 23)$ in the bPITC $(p=0.0001)$, respectively.

\section{Linkage to HIV care and treatment}

In the tPITC group, $85.0 \%(34 / 40)$ of children tested $\mathrm{HIV}+$ were linked to HIV treatment compared to $52.5 \%$ $(21 / 40)$ of the cases in the bPITC $(p=0.0018)$ (Table 2$)$.

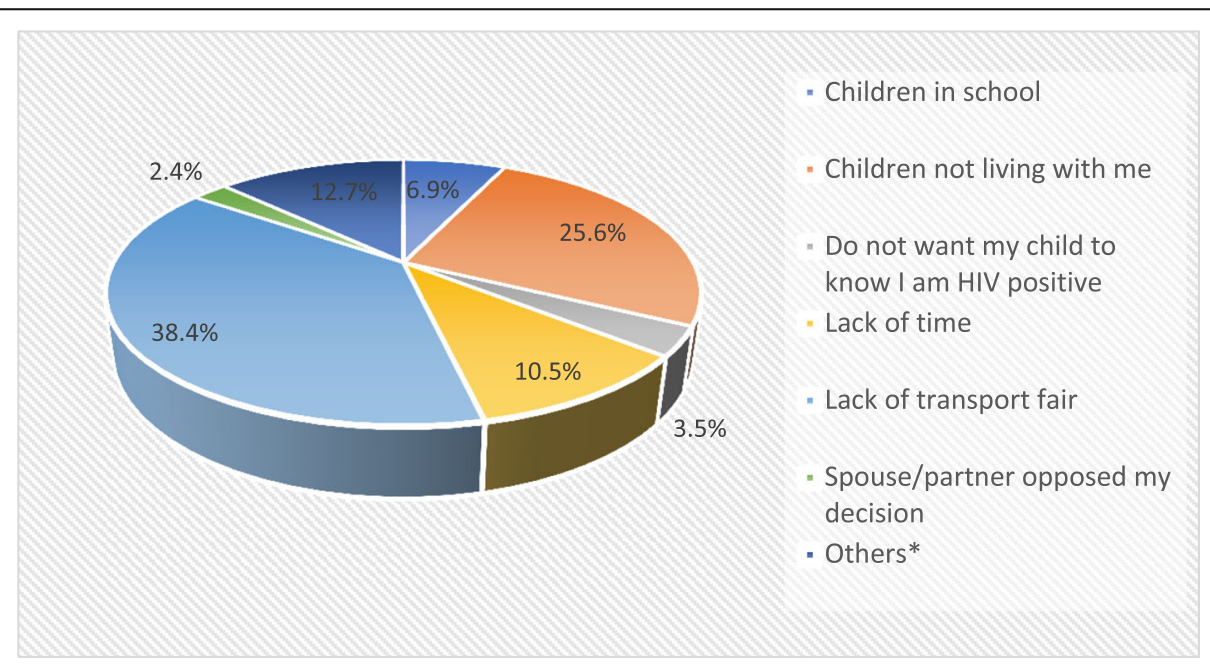

Fig. 2 Reasons of PLHIV for not returning with children for HIV testing, ASPA study, July 2015-November 2016, Cameroon 
Among children $\leq 12$ years, the linkage rate was $90.3 \%$ vs $58.6 \%(p=0.005)$ in the tPITC and bPITC groups, respectively. Among children older than 12 years, this rate was $66.7 \%$ vs. $36.4 \%(p=0.3698)$ in the tPITC and bPITC groups, respectively.

\section{Discussion}

Applying the ambitious 90-90-90 target of the UNAIDS [13] to pediatrics would require global identification of 3.7 million infants, children and adolescents with HIV infection, treatment of 3.3 million, and achieving viral suppression among 3 million within the next four years [14]. Pediatric HIV case finding represents a major challenge in meeting these targets. The findings of this study add to the growing evidence that targeted strategies may increase HIV testing uptake, yield and linkage to treatment.

In the tPITC group, we found an HIV positivity rate (case detection rate/yield) of 3.5\%, which was closer to the $4.0 \%$ but lower than the 7.4\% reported by Saeed et al. in Malawi [15] and Wagner et al.in Kenya [16], respectively. The HIV prevalence (4.3\%) in the general population in Cameroon (4.3\%) [17] is lower compared to Malawi (9.2\%) and Kenya (5.4\%) [8] and this may explain the lower HIV positivity rate observed among the pediatric and adolescent population in our study compared to Malawi and Kenya as reported in the aforementioned studies. In the bPITC group, we found a prevalence of $1.6 \%$, which was similar to the $1.8 \%$ reported by Zoufaly et al. in rural Cameroon [18] and closer to the $2.7 \%$ reported by Cohn et al. in a meta-analysis [19].

The HIV positivity rates reported by this study imply that the yield of newly identified HIV cases among children was two times higher with tPITC. To identify a new HIV case, 31 and 62 parents have to be counselled, and 29 and 63 children have to be tested, in the tPITC and bPITC groups, respectively. Therefore, less effort is needed with TPITC to identify a new pediatric or adolescent HIV case, and tPITC is more effective than bPITC in the context of our study.

The parents' acceptance (acceptability) of HIV testing for their children was very high using both strategies (99.7\% in tPITC vs $98.8 \%$ in bPITC). The slightly higher acceptance in the tPITC group may be due to enhanced HIV awareness resulting from the contact of these parents with HIV services. Ahmed et al. reported a similar high acceptability (93.5\%) in their study in Malawi [15].

The uptake of HIV testing (feasibility) among children was significantly lower in the tPITC group $(56.7 \%$ vs $90.3 \%, p<0.0001)$. This may be attributable to the fact that the tPITC parents living with HIV were initially seen in the hospital in the first place for their own care, and their children were less likely to be present. Similarly, low uptake of HIV testing among children in tPITC was reported in Kenya where only 14\% of parents who had initially consented to test children had followed through with the testing [16]. In our study, according to the parents' declarations, the main reasons for their inability to return to the hospital with their children for HIV testing included the lack of transport fare (38.3\%), children not living with them (25.6\%), and the lack of time (10.5\%). These reasons should be taken with caution because the HIV testing uptake could have also been limited by parental' levels barriers, notably fear of self-disclosure, stigma and discrimination as reported by previous studies $[4,16,20-22]$. There is a need for qualitative research to provide in-depth information on parental barriers to the uptake of HIV testing for children in the context of tPITC approach implementation.

Although the HIV testing uptake was highest (90.3\%) in the bPITC, nearly $10 \%$ of the children enrolled were not ultimately tested. This finding was attributable to a fraction of parents who initially consented to test their children, but they subsequently changed their decisions and did not go to the laboratory for testing. A number may have gone to the laboratory, but due to the long waiting time, they may have decided to leave without testing the child. Conducting the HIV testing on the spot or having a dedicated testing room for these children near the counseling office may have reduced the missed opportunity for testing.

In this study, pediatric HIV cases were diagnosed earlier in the TPITC group ( $84.8 \%$ at WHO stage 1$)$ because this strategy tested asymptomatic children in contrast to the BPITC, in which children tested were evaluated for an illness $(34.8 \%$ at WHO stage 2 and $39.1 \%$ at WHO stage 3). This finding was consistent with a previous targeted pediatric HIV testing in Malawi, where a large proportion (46.7\%) of HIV infected children were diagnosed at WHO stage 1 [15]. Therefore, a pediatric HIV program could prioritize the tPITC strategy for early case identification as a means to reduce the high mortality rate associated with non-treatment of children living with HIV [23-25]. Linkage to care was significantly higher in the tPITC group (85.0\% vs $52.5 \%, p=0.0018$ ). This finding may be explained by the fact that the large majority of parents were already in HIV care $(96 \%$ of children were identified through parents on ART) and it was easier to link the children to HIV services because the parents, having seen the benefit of ART, quickly seized the treatment opportunity offered for their children who tested positive for HIV. This finding highlights the potential effect that prior enrolment of parents on ART could have on linkage of their children to care. This further demonstrates the effectiveness of the HIV care family-centered approach in enhancing pediatric HIV linkage and retention in care [26-29]. Nevertheless, in Limbe Regional Hospital, the linkage rate was statistically similar in the tPITC and bPITC groups $(20.0 \%$ vs $21.4 \%, p=1)$, 
but this rate was higher (but not statistically significant) in the tPITC group in Abong-Mbang (92.9\% vs $76.2 \%, p=$ $0.2054)$ and significantly higher in Ndop $(95.2 \%$ vs $40.0 \%$, $p=0.0144$ ) district hospital. In Abong-Mbang and Ndop district hospitals, we assigned staff members (linkage agents) to ensure that all children who tested positive for HIV were linked to care. Moreover, in these two new sites (through the humanitarian component of the ASPA project), nutritional kits were provided to HIV-positive children in care. Neither the linkage agent nor the nutritional support was provided at the Limbe Regional Hospital, which had the lowest linkage rate among the three sites. This finding suggests that both the linkage agent and nutritional support may have contributed meaningfully in improving linkage in the TPITC and bPITC groups. The positive effect of nutritional support in the linkage and retention of children in care has been previously demonstrated [30]. There is a need to further investigate this effect when combined with a linkage agent.

The limitations of this study were that the Limbe Regional Hospital began implementation in July 2015, while the Abong-Mbang and Ndop District Hospitals began later, in June 2016. We tweaked the implementation strategies in these 2 additional sites from lessons learned from the first site. In particular, we reinforced the follow-up of children diagnosed HIV+ to enhance linkage (introduction of a linkage agent). We also introduced the provision of nutritional kits to HIV+ children in care. These additional interventions may have contributed to increase the linkage rate in these 2 sites compared to Limbe. Thus, the results of Limbe Regional Hospital and that of Abong-Mbang and Ndop District Hospital are not comparable in all aspects. Nevertheless, because the primary objective of the study was not to compare the outcome per site, but rather, to compare the outcome of both IPITC and bPITC, the time difference in implementation per site did not affect the results of the study. In contrast, this stepwise implementation approach was found very useful because lessons learned from the first site (Limbe) informed the adjustments needed to have a more robust strategy for better linkage to care of HIV-positive children. Another potential limitation was that critically ill children were not included in our study. However, the number of these children coming to the hospital is usually marginal and their exclusion would not have affected our findings.

\section{Conclusions}

The tPITC and bPITC strategies were highly acceptable to parents to support HIV testing for their children. The tPITC had a higher yield and provided an opportunity for early detection of pediatric and adolescent HIV cases as well as linkage to care before these children become sick and present to the health facility with HIV clinical manifestations.

However, the feasibility of tPITC strategy was lower compared to bPITC, which was due to the low HIV testing uptake among children and adolescents in the former strategy. The bPITC had a higher HIV testing uptake, but a lower linkage rate. Thus, the clinical cascade for the tPITC is challenged by the HIV testing uptake gap while that of the bPITC is constrained by the ART linkage gap.

Overall, the ASPA study demonstrated the superiority of tPITC over bPITC in terms of case detection, case detection earliness, and linkage to care and treatment. However, when the required resources are available, both strategies may be promoted to fast track the achievement of the ambitious 90-90-90 targets of the UNAIDS among children and adolescents by 2020 . Meeting this objective would require the implementation of strategies that are suitable to optimize the outcome of both tPITC and bPITC approaches by improving the HIV testing uptake and linkage to care and treatment, respectively.

\section{Additional files}

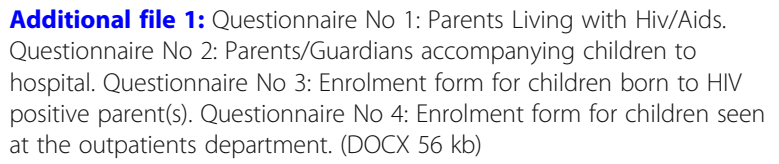

Additional file 2: Questionnaire No 5: Survey parents living with HIV/ AIDS Questionnaire. (DOCX $20 \mathrm{~kb}$ )

\section{Abbreviations}

ANC: Antenatal Consultations; ART: Antiretroviral therapy; ARV: Antiretroviral Drugs; ASPA: Active Search for Pediatric HIV/AIDS; bPITC: Blanket providerinitiated testing and counseling; CD4: Cluster of differentiation 4;

$\mathrm{Cl}$ : Confidence Interval; DBS: Dot blot spot; DNA: Deoxyribonucleic acid; EID: Early Infant Diagnosis; HIV/AIDS: Human Immunodeficiency Virus/ Acquired Immune Deficiency Syndrome; LRH: Limbe Regional Hospital; MTCT: Mother to Child Transmission of HIV; NDH: Ndop District Hospital; OPD: Outpatient Department; PCR: Polymerase chain reaction; PITC: Providerinitiated testing and counseling; PLHIV: People Living with HIV/AIDS; PMTCT: Prevention of Mother to Child Transmission of HIV; R4D : Research for Development International; RT1 : Rapid test 1; RT2: Rapid test 2; tPITC: Targeted provider- initiated testing and counseling; UNAIDS: The Joint United Nations Programme on HIV and AIDS; UNICEF: The United Nations Children's Fund; WHO: The World Health Organization

\section{Acknowledgments}

This study constitutes a part of the PhD Medical Research-International Health dissertation of Dr. Habakkuk Azinyui Yumo (Corresponding Author) at the Center for International Health $(\mathrm{ClH})$ - Ludwig Maximilian Universität in Muenchen (Germany). He is thankful to Prof. Michael Loescher, $\mathrm{ClH}$ chair and all the lecturers of the PhD Medical Research-International Health for guidance and support. He is also very appreciative of the following experts who provided comments on the manuscript: Dr. Mamadou Otto Diallo, Medical Officer, CDC Atlanta, GA, USA; Prof. Dr. Jan Hendrik Richardus, Department of Public Health, Erasmus MC, University Medical Center Rotterdam, The Netherlands; Dr. Michael R. Jordan, Assistant Professor of Medicine, Tufts University School of Medicine, Boston, MA; and Dr. Isidore Sieleunou, Global Health Research Fellow, University of Montreal and R4D International, Yaounde, Cameroon. 
The authors are very thankful to all of the parents and children who participated in this study. We thank all of the health personnel of the Limbe Regional Hospital, Abong-Mbang and Ndop District Hospitals for their collaboration. In particular, the Directors of the respective hospitals: Dr. Bijingni Kuwoh Pius (Limbe), Dr. Nsame Denis (Abong-Mbang) and Dr. Kwa Kedze (Ndop). The authors also appreciate the role of Dr. Titus Sabi (Camformedics e.V.), that of the ASPA Study Central Coordination Team at R4D International Foundation (Yaoundé) and all of the coordinators and research officers/data clerks of the respective sites listed as follows: Dr. Marie Balimba Njabon, Rachel Tita and Ernestine Kendowo (Limbe Regional Hospital); Ndenkeh N. Jackson Jr., Gibero Tieseh Tandar, Moabande epse Kiringa Florence Gladys (Abong-Mbang District Hospital); Prisca MbahFongkimeh Ngetemalah, Violet Mezepahyui Yumo, Wilson Nyifunda Kenyenyen, Salioh Mbinyui Mbuh (Ndop District Hospital); Hilton Nchotou Ndimuangu, Mark Benwi, Leonard Ndongo (R4D International Foundation).

\section{Funding}

The ASPA study was co-funded by: i) the Central Africa leDEA (U01 Al096299) funded by the US National Institute of Health $(\mathrm{NIH})$ through Albert Einstein College of Medicine, Bronx, New York; ii) the Else Kroener-Fresenius-Stiftung (Bad Homburg, Germany) and iii) R4D International Foundation (Yaounde, Cameroon). Camformedics e.V. (Essen, Germany) coordinated the management of the study funds between the Else Kroener-Fresenius-Stiftung and R4D International Foundation.

\section{Availability of data and materials}

The datasets used and/or analyzed during the current study are available from the corresponding author on reasonable request.

\section{Authors' contributions}

HAY: conceived, conceptualized and designed the study, drafted the study protocol, fundraised for the study, recruited and trained study staff, supervised data acquisition, analyzed data, interpreted the results and drafted the manuscript. CK: reviewed the study protocol, interpreted the results and reviewed the manuscript. RAA: co-supervised data acquisition, interpreted the results and reviewed the manuscript. AMN: supported data analysis, interpreted the results and reviewed the manuscript. MB: reviewed the study protocol, interpreted the results and reviewed the manuscript. DN: interpreted the results and reviewed the manuscript. KA: interpreted the results and reviewed the manuscript. TL: reviewed the study protocol, interpreted the results and reviewed the manuscript. All authors read and approved the final manuscript.

\section{Ethics approval and consent to participate}

Participation in the study was voluntary for both parents and children. Only parents who consented were enrolled and assent was requested from children above 11 years of age. Consent from parents was obtained via signed written consent form. Likewise, assent for children over the age of 11 was obtained through a signed written assent form. The ASPA study received ethical approval from the Cameroon National Ethics Committee, the Ludwig-Maximilians-Universität, Munich (Germany) and the Albert Einstein College of Medicine (NY, U.S.)

\section{Consent for publication}

This is not applicable because our manuscript does not contain any individual person's data in any form (including individual details, images or videos).

\section{Competing interests}

The authors declare that they have no competing interests.

\section{Publisher's Note}

Springer Nature remains neutral with regard to jurisdictional claims in published maps and institutional affiliations.

\section{Author details}

${ }^{1}$ R4D International Foundation, Yaounde, Cameroon. ${ }^{2}$ Center for International Health $(\mathrm{ClH})$, Ludwig-Maximilians-Universität, München, Germany. ${ }^{3}$ Faculty of Health Sciences, University of Bamenda, Bamenda, Cameroon. ${ }^{4}$ University of Yaounde I, Yaounde, Cameroon. ${ }^{5}$ CUNY Graduate School of Public Health and Health Policy, New York, USA. ${ }^{6}$ Department of Epidemiology \&
Population Health, Albert Einstein College of Medicine, New York, USA. ${ }^{7}$ Montefiore Medical Center, New York, USA.

Received: 25 January 2018 Accepted: 4 September 2018

Published online: 25 September 2018

\section{References}

1. Davies M-A, Kalk E. Provider-initiated HIV testing and counselling for children. PLoS Med. 2014;11(5):e1001650. https://doi.org/10.1371/journal. pmed.1001650.

2. UNICEF. For Every Child, End AIDS. Seventh Stocktaking Report. New York: UNICEF; 2016. https://data.unicef.org/wp-content/uploads/2016/12/HIV-andAIDS-2016-Seventh-Stocktaking-Report.pdf. Accessed 07 Sept 2018.

3. UNICEF. Towards an AIDS-free generation Children and AIDS. Sixth Stocktaking Report. New York: UNICEF; 2013. https://www.unicef.org/ publications/files/Children_and_AIDS_Sixth_Stocktaking_Report_EN.pdf Accessed 07 Sept 2018.

4. Ahmed S, Kim MH, Sugandhi N, Phelps BR, Sabelli R, Diallo MO, et al. Beyond early infant diagnosis: case finding strategies for identification of HIV-infected infants and children. AIDS Lond Engl. 2013;27(0 2):S235-45. https://doi.org/10.1097/QAD.0000000000000099.

5. Leon N, Lewin S, Mathews C. Implementing a provider-initiated testing and counselling (PITC) intervention in Cape town, South Africa: a process evaluation using the normalisation process model. Implementation Science. 2013;8:97

6. UNAIDS. Fact sheet 2016. Geneva: UNAIDS; 2016. www.unaids.org/sites/ default/files/media_asset/20150901_FactSheet_2015_en.pdf. Accessed 07 Sept 2018.

7. UNAIDS. Fact Sheet World AIDS 2017. Geneva: UNAIDS; 2017. http://www. unaids.org/sites/default/files/media_asset/UNAIDS_FactSheet_en.pdf. Accessed 13 Aug 2017

8. UNAIDS. Country Fact Sheet Cameroon 2016. AIDSinfo. http://aidsinfo. unaids.org. Accessed 22 Sept 2017.

9. UNAIDS. 2008 Report on the Global AIDS Epidemic. Geneva: UNAIDS; 2008. http:/www.unaids.org/sites/default/files/media_asset/jc1510_2008globalreport en_0.pdf. Accessed 07 Sept 2018.

10. Yumo HA, Angwafor SA, Ayuk EM, Ndang CA. Scaling up paediatric HIV care and treatment in resource limited settings: Lessons learned from the active search for pediatric AIDS in a rural health district in northwestern Cameroon. Dakar (Senegal):2nd international interest workshop; 2008.

11. WHO and UNICEF. Policy Requirements for HIV testing and Counselling of Infants and Young Children in Health Facilities. Geneva: WHO and UNICEF 2010. http://apps.who.int/iris/bitstream/10665/44276/1/9789241599092_eng. pdf. Accessed 07 Sept 2018.

12. Wang $\mathrm{H}$, Chow SC. Sample size calculation for comparing proportions. Wiley Encyclopedia of Clinical Trials 2007. https://doi.org/10.1002/ 9781118445112.stat07091.

13. UNAIDS. 90-90-90-an ambitious treatment target to help end the AIDS epidemic. Geneva: UNAIDS; 2017. http://www.unaids.org/en/resources/ documents/2017/90-90-90. Accessed 07 Sept 2018.

14. Abrams EJ, Strasser S. 90-90-90 - Charting a steady course to end the paediatric HIV epidemic. J Int AIDS Soc. 2015;18(Suppl 6):20296. https://doi. org/10.7448/IAS.18.7.2029.

15. Ahmed S, Sabelli RA, Simon K, Rosenberg NE, Kavuta E, Harawa M, et al. Index case finding facilitates identification and linkage to care of children and young persons living with HIV/AIDS in Malawi. Tropical Med Int Health. 2017;22(8):1021-9. https://doi.org/10.1111/tmi.12900.

16. Wagner AD, Mugo C, Njuguna IN, Maleche-obimbo E, Sherr K, Inwani IW, et al. Implementation and operational research: active referral of children of Hiv-positive adults reveals high prevalence of undiagnosed Hiv. J Acquir Immune Defic Syndr. 2016;73(5):e83-9. https://doi.org/10.1097/QAl. 0000000000001184

17. Republic of Cameroon. Cameroun Enquête Démographique et de Santé et à Indicateurs Multiples 2011. Maryland: INS-ICF International Calverton; 2012 https://dhsprogram.com/pubs/pdf/FR260/FR260.pdf. Accessed 07 Sept 2018.

18. Zoufaly A, Hammerl R, Sunjoh F, Jochum J, Nassimi N, Awasom C, et al. High HIV prevalence among children presenting for general consultation in rural Cameroon. Int J STD AIDS. 2014;25(10):742-4. https://doi.org/10.1177/ 0956462413518762

19. Cohn J, Whitehouse K, Tuttle J, Lueck K, Tran T. Paediatric HIV testing beyond the context of prevention of mother-to-child transmission: a 
systematic review and meta-analysis. Lancet HIV. 2016 (10):e473-81. https:// doi.org/10.1016/52352-3018(16)30050-9.

20. Rwemisisi J, Wolff B, Coutinho A, Grosskurth H, Whitworth J. "What if they ask how I got it?" dilemmas of disclosing parental HIV status and testing children for HIV in Uganda. Health policy plan. Health Policy Plan. 2008;23(1):36-42.

21. Buzdugan $\mathrm{R}$, Watadzaushe $\mathrm{C}$, Dirawo J, Mundida O, Langhaug L, Willis $\mathrm{N}$, et al. Positive attitudes to pediatric HIV testing: findings from a nationally representative survey from Zimbabwe. PLoS One. 2012;7(12):e53213. https:// doi.org/10.1371/journal.pone.0053213.

22. John-Stewart GC, Wariua G, Beima-Sofie KM, Richardson BA, Farquhar C, Maleche-Obimbo E, et al. Prevalence, perceptions, and correlates of pediatric HIV disclosure in an HIV treatment program in Kenya. AIDS Care. 2013;25(9):1067-76. https://doi.org/10.1080/09540121.2012.749333.

23. Newell M-L, Brahmbhatt H, Ghys PD. Child mortality and HIV infection in Africa: a review. AIDS. 2004;18(Suppl 2):S27-34

24. Lallemant C, Halembokaka G, Baty G, Ngo-Giang-Huong N, Barin F, Le Coeur S. Impact of HIV/Aids on child mortality before the highly active antiretroviral therapy era: a study in Pointe-Noire, republic of Congo. J Trop Med. 2010;2010. https://doi.org/10.1155/2010/897176.

25. Wagner A, Slyker J, Langat A, Inwani I, Adhiambo J, Benki-Nugent S, et al. High mortality in HIV-infected children diagnosed in hospital underscores need for faster diagnostic turnaround time in prevention of mother-to-child transmission of HIV (PMTCT) programs. BMC Pediatr. 2015;15:10. https://doi. org/10.1186/s12887-015-0325-8.

26. Phelps BR, Ahmed S, Amzel A, Diallo MO, Jacobs T, Kellerman SE, et al. Linkage, initiation and retention of children in the antiretroviral therapy cascade: an overview. AIDS Lond Engl. 2013;27(02):S207-13. https://doi.org/ 10.1097/QAD.0000000000000095.

27. Ruria EC, Masaba R, Kose J, Woelk G, Mwangi E, Matu L, et al. Optimizing linkage to care and initiation and retention on treatment of adolescents with newly diagnosed HIV infection. AIDS Lond Engl. 2017;31(Suppl 3): S253-60. https://doi.org/10.1097/QAD.0000000000001538.

28. Carmone A, Bomai K, Bongi W, Frank TD, Dalepa H, Loifa B, et al. Partner testing, linkage to care, and HIV-free survival in a program to prevent parent-to-child transmission of HIV in the highlands of Papua New Guinea. Glob Health Action. 2014;7:24995. https://doi.org/10.3402/gha.v7.24995.

29. Luyirika E, Towle MS, Achan J, Muhangi J, Senyimba C, Lule F, et al. Scaling up Paediatric HIV care with an integrated, family-Centred approach: an observational case study from Uganda. PLoS One. 8(8):e69548. https://doi. org/10.1371/journal.pone.0069548.

30. Kranzer K, Meghji J, Bandason T, Dauya E, Mungofa S, Busza J, et al. Barriers to provider-initiated testing and counselling for children in a high HIV prevalence setting: a mixed methods study. PLoS Med. 11(5):e1001649. https://doi.org/10.1371/journal.pmed.1001649.

Ready to submit your research? Choose BMC and benefit from:

- fast, convenient online submission

- thorough peer review by experienced researchers in your field

- rapid publication on acceptance

- support for research data, including large and complex data types

- gold Open Access which fosters wider collaboration and increased citations

- maximum visibility for your research: over $100 \mathrm{M}$ website views per year

At $\mathrm{BMC}$, research is always in progress.

Learn more biomedcentral.com/submissions 